\title{
When is a personal care task not just a task?
}

\author{
Can undertaking personal care within \\ practice learning opportunities enhance the \\ learning of student social workers?
}

\section{Jane Fenton $^{1}$ and Linda Walker ${ }^{2}$}

Abstract: This small scale study examined social work students' attitudes to undertaking personal care tasks whilst involved in practice learning opportunities (PLOs) in private sector residential care, mostly with older people. A rationale for placing students in residential settings, within the requirements of social work education in Scotland, and the value of this for their learning, is explored. The authors then examine why students should be involved in undertaking personal care. A literature review highlights the main areas of study, namely value-behaviour congruence, notions of professionalism and the interface with managerialism, and the importance of an 'ethics of care' approach.

The main findings from the study centred around the process of attaining value-behaviour congruence, the transformation of students' attitudes from negative to positive, the centrality of relationship building and explicit values, a generalised lack of acquiring or drawing on formal academic knowledge, and factors associated with an emergent social work professional.

\section{Key words:}

1. Lecturer, School of Education, Social Work and Community Education, University of Dundee

2. Associate Dean, School of Education, Social Work and Community Education, University of Dundee

Address for Correspondence: Jane Fenton, School of Education, Social Work and Community Education, University of Dundee, Dundee DD1 4HN. j.fenton@dundee.ac.uk

19 J. of Practice Teaching \& Learning 11 (1), pp.19-36. DOI: 10.1921/ 175951511X651913. @ wEbb 
Jane Fenton and Linda Walker

\section{Introduction}

This paper focuses on the experiences of student social workers undertaking personal care tasks. The service user on the receiving end of this type of care, with initially reluctant students, is an additional and very important area for exploration in its own right which this paper does not have scope to investigate. Practice educators and link workers in the PLO settings did, however, ensure that no students were asked to complete these tasks until they felt comfortable doing so and had begun to make positive relationships with service users. The students had also spent time 'shadowing' experienced workers and had undertaken 'moving and handling' training (as per new social care workers).

Personal care is free in Scotland, as recommended by the Royal Commission on Long Term Care (1999) who viewed the provision of personal care as a moral right (akin to free health care), and central to issues of 'self-respect, dignity and choice' (par 6.35). Examining the issue of personal care further, the National Care Standards, 16.7, state: 'Intimate physical care or treatment will be carried out sensitively and in private, in a way which maintains your dignity' (Care Commission, 2007). The Scottish Social Services Council Code of Practice 1.4, states that workers must be engaged in 'Respecting and maintaining the dignity and privacy of service users' (SSSC, 2009); the Association of Directors of Social Work states that, in terms of all social work, 'there should be a positive focus on a sense of well-being' (ADSW, 2009, p.3); and the International Federation of Social Work code of ethics, ratified by the British Association of Social Work suggests social work is about 'helping with personal and social needs'(BASW, 2010). It is clear, therefore, that the activity of providing personal care is exactly congruent with social work's value and ethical framework.

Undertaking personal care is a central aspect of the work with older people in residential care, and the majority of the students in our sample were placed in such establishments. The students expressed disappointment with their allocated PLOs and, therefore, we were challenged to explore firstly whether such a setting was appropriate and secondly, beyond the consonance of personal care with social work values, were there other robust reasons for expecting students to be involved in this type of work?

20 J. of Practice Teaching \& Learning 11 (1), pp.19-36. DOI: 10.1921/ 175951511X651913. @ wEb 


\section{'Appropriate' setting?}

Quinn (1999) found that student social workers were reluctant to work with older people. She explored the idea that this was because people were reminded of their own mortality and shied away from the experience for that reason. However, she found that, actually, students were keen to work with people who were dying, because that work was perceived as interesting and challenging. Working with older people, however, was seen as mundane, uninteresting and depressing. Hughes and Haycox (2006) echoed these findings, when their study again suggested significant student reluctance to working with older people. Quinn unravels this issue further, by exploring it in terms of student attitudes. Beliefs about older people can be challenged, but 'attitude' has an emotional component less open to change through learning new facts. Quinn found that students who chose the university elective about older people were usually students who had had experience in the area, and were committed to it. Both studies demonstrate that the best way to influence the negative and stereotypical attitudes held by the students was by giving them direct experience of working with older people.

Also, The Framework for Social Work Education in Scotland (Scottish Government, 2003) which enshrines the Standards in Social Work Education (SiSWE) requires qualifying programmes to offer practice opportunities in at least two contrasting service delivery settings and to allow students to work with at least two user groups and within services that take account of and value diversity. Additionally, the guiding principles within the Framework focus on relationship building across several domains with service users and carers at the heart of this endeavour.

Social work services are designed for people and they depend essentially on people. How to work with people using services, carers, professional colleagues and volunteers, and work closely in partnership with them is central to the SiSWE. (Scottish Government, 2003, p.20)

Using high quality residential care agencies, in our view, not only met the requirements of the Framework in regard to work in diverse settings, but also provided students with rich opportunities to build positive relationships with service users. It also provided a context within which any preconceived, negative attitudes to older people could be challenged.

The above evidence, then, gives us a rationale for promoting direct work

21 J. of Practice Teaching \& Learning 11(1), pp.19-36. DOI: 10.1921/ 175951511X651913. @ wEb 
with older people in residential settings, an environment most conducive to real face-to-face relationship building work. It does not, however, answer the question about why, within that explicit relationship-building context, students should be expected to undertake personal care.

\section{Why personal care?}

\section{To attain value/behaviour congruence}

DiFranks (2008) undertook a study looking at the value-beliefs and expected work behaviour of 500 social workers in America. As a result of the study, DiFranks uncovered the concept of 'disjuncture' - a feeling of ethical stress when values and behaviour are in conflict. DiFranks found that when social workers had to undertake tasks (most often managerial, gate-keeping tasks) which did not feel congruent with their value beliefs, they suffered quite significant ethical stress or 'disjuncture'. DiFranks also found that the opposite was true, when values and actions were congruent, workers felt low or negligible ethical stress. Other studies echo these findings (eg. Jones, 2001; O'Donnell et al., 2008, Calderwood et al., 2009) and culminate in a body of literature consistent in its messages regarding disjuncture. There also appears to be a particularly powerful theme characterised by workers being able to 'help' when required. It appears that if workers feel able to properly help, disjuncture is significantly reduced (Fenton, 2011). Kosny and Eakin (2008) studied several agencies in Canada where workers were encouraged to help when they could, to 'muck in' and respond appropriately to each individual. Task boundaries were permeable and workers were fully able to practice in accordance with their value beliefs. Workers reported very low levels of stress and appeared to be extremely resilient, reporting high levels of satisfaction with their work. The key finding, according to Kosny and Eakin, was that the congruence of values and behaviour (for example, helping when required) led to a very fulfilling experience for workers.

Can this persuasive body of literature be applied to personal care in residential establishments? If it has been established that giving personal care is in tune with social work values and that students would be expected to be centrally concerned with building relationships with residents, then it might be hypothesised that giving personal care, in the context of that relationship, should be satisfying and fulfilling for students. A clearer

22 J. of Practice Teaching \& Learning 11(1), pp.19-36. DOI: 10.1921/ 175951511X651913. @ w\&b 
example of being able to 'help' would indeed be difficult to find.

Looking at the literature and ideas explored thus far, then, we could suggest that students would transit through three stages in relation to personal care:

- reluctance and disappointment with the placement location and service user group - perhaps exacerbated by the thought of unpleasant and mundane care tasks

- actually undertaking personal care once relationships with residents are established - feeling the 'rightness' of wanting to 'help'

- feeling satisfied having 'helped' satisfactorily

Finally, the importance of a fourth stage should be highlighted - reflection on, and understanding of, the importance of value/behaviour congruence. A student should be helped by a practice educator to understand this concept as well as to appreciate how values associated with carrying out personal care such as dignity, respect and choice are integral to the task and a rich source of learning.

Is the suggestion that the undertaking of personal care tasks should engender feelings of value-behaviour congruence in students a sufficient rationale for recommending that students should be encouraged to undertake these tasks as part of their PLOs? If not, then other key concepts can be examined as follows.

\section{Professionalism}

Van Lanen (2008 p. 470) states 'Professionalism...refers to the situation in which workers themselves are in possession of the specialised knowledge that is required for their work and are in possession of the discretionary power to organise their own conditions of work as opposed to being... subject to the will of... managers'.

Many authors, however, have written about the advancement of an overpowering managerialism which threatens the above definition of professionalism and its characteristics of knowledge and autonomy (for example, Jones, 2001, Sawyer, 2010 and many more). Meagher and Parton (2004) describe managerialism as a 'top-down' approach, emphasising social workers' accountability to employers not service-users. There is a legal and evidence-based-practice aspiration, which further encourages an impersonal, instrumental and technical approach. Meagher and

23 J. of Practice Teaching \& Learning 11(1), pp.19-36. DOI: 10.1921/ 175951511X651913. @ wEb 
Parton also suggest that social work, as a discipline, attempted to become more professional in the 20th century but did not reach the same status as, for example, medicine and always remained at the level of bureauprofessionalism - that is, contained elements of bureaucracy as well as professionalism. Bureaucracy emphasises formality, distance, hierarchy and impersonal decision making. Relational and contextual factors are ignored. Professionalism, although it does not bow down to the hierarchy, can, in some definitions, contain elements such as 'professional distance', impassivity (in the face of pain) and the like which resonates more with bureaucracy than with Van Lanen's definition of professionalism. As social work educators, we need to continue to emphasise that to be a professional social worker, the relationship with the service-user is central. As Meagher and Parton suggest, rather than this being the element that gets in the way of social work being a true profession (in terms of the bureaucratic definition), it should unashamedly be the defining feature.

How then can students be helped to move away from an idea of bureaucracy as professionalism to a notion of professionalism which centralises the relationship with the service user, and includes knowledge, values and autonomy? Schwartz (1994) suggested social workers themselves have underplayed the complex nature of their role resulting in it being marginalised as a 'semi-profession'. He argues it is the very fact of centralising the service user whilst bringing together notions of autonomy, values and depth of knowledge that make it unique. To return again to the idea of social work students undertaking personal care tasks, it is suggested that students can be helped to understand that such a task is actually much more than practical 'doing'. Thinking about it in terms of professional social work, the student, to be truly professional, would be expected to:

1. build a relationship with the service user (the central and most important feature);

2. acquire knowledge essential for understanding the service-user's experience of requiring and receiving personal care and thus help the service-user with the associated issues (such as life transitions, theories of loss and so on);

3. explicitly employ social work values to underpin their work (for example, dignity, respect, privacy); and

4. be autonomous in their thinking - are they doing this because it is the 'right' thing to do and that to 'help' feels correct in terms of value and behaviour congruence?

24 J. of Practice Teaching \& Learning 11 (1), pp. 19-36. DOI: 10.1921/ 175951511X651913. @ w\&b 
If students can be helped to analyse their practice in this way, recognising and integrating the complexities, they may also be helped to understand and resist the onslaught of bureaucratic managerialism, and to nurture and grow their own sense of firmly grounded social work professionalism.

Another key-concept illuminating why students should undertake personal care, is the possibility of personal care helping students develop a framework for social work based on an 'ethics of care' approach.

\section{An ethics of care approach}

Meagher and Parton (2004) suggest that we need to resurrect the central idea of social work as a 'caring' profession. They recognise that this notion does not sit well with managerialism and feel strongly that in order to counter the advancement of such a culture, a commitment to care must be re-established: 'rehabilitating the ideal of care can counterbalance pervasive and corrosive managerialism' (p. 11). It is suggested that unless care is once again central, social work's distinctiveness will be lost.

A thorough exploration of the 'ethics of care' approach, and its essential feminist underpinnings, is not possible within this paper (Manning, 1998; Horner and Kelly, 2007). However, in essence, an 'ethics of care' approach emphasises the relationship between the worker and service user, and considers all the relationships that the service user has as essential to decision making and the understanding of that person. It is a 'feminine' approach, which is contrasted with the masculine 'ethics of justice' characterised by following ethical principles in a detached and objective way (Manning, 1998). Herein, we can see how a 'justice' approach resonates with the (masculine?) idea of bureaucracy-professionalismmanagerialism and how a 'care' approach is congruent with the idea of social work professionalism. According to Manning, the ethics of care involves moral attention to the person and the situation in all its complexity, sympathetic understanding, an attempt to identify with the service user and relationship awareness. Manning suggests that in order to apply an ethics of care framework, a person must have time to really get to know the service user, to build a relationship with them and other important people in the situation and to build mutual trust. Manning states that we must also be aware of the 'comfort' of the service user and to do this, it is essential that we can attend to all needs when required. Therefore, to truly practise from an ethics of care basis, a worker must be aware of the

25 J. of Practice Teaching \& Learning 11(1), pp.19-36. DOI: 10.1921/ 175951511X651913. @ wEbb 
importance of meeting those basic needs, and should be prepared to do so in the appropriate context. In summary, then, providing personal care in the context of a relationship would be absolutely consonant with an ethics of care approach. It is suggested that such an approach can 'provide a key critical framework for both analysing and moving beyond the current dominance of the managerial approaches to social work.' (Meagher and Parton, p. 24)

Finally, it is proposed that a further reason for asking students to undertake personal care is that in doing so, students would generate many rich learning experiences from which to evidence their attainment of the SiSWE.

\section{Links to the SiSWE}

Following completion of all practice learning opportunities, students within this study were required to write about their experiences in an assessed piece of work known as their 'Articulation of Practice' (AofP). Through a 7,500 word account they had to evidence their learning matched against the 6 Key Roles and 22 learning Foci set out in the SiSWE within the Framework for Social Work Education in Scotland (Scottish Government, 2003) Additionally, they had to provide evidence of how they have worked in an ethical manner, taking account of the Scottish Social Services Council (SSSC) Codes of Practice. The AofP incorporates a reflective account and an academic analysis of their experience and work undertaken.

Opportunities abound within the SiSWE to make direct links to student learning from personal care tasks as seen from the example below:

Key Role 2

Plan, carry out, review and evaluate social work practice with individuals, families, carers, groups, communities and other professionals

Learning Foci

2a Develop relationships with individuals, families, carers, groups and communities that show respect for diversity, equality, dignity and privacy

2b Maintain purposeful relationships for as long as is necessary' (Scottish Government, 2003)

26 J. of Practice Teaching \& Learning 11(1), pp.19-36. DOI: 10.1921/ 175951511X651913. ๑ w\&b 
Many other examples of appropriate SiSWE would also apply depending on the exact circumstances.

Given the good 'fit' between personal care and the above required evidence for SiSWE, it was felt that students could successfully demonstrate their learning in the manner required by the SSSC whilst at the same time experience profound learning as individuals, as outlined previously.

\section{Summary}

In summary, then, the question of why students should undertake personal care tasks has been addressed by suggesting that students will have opportunities to access four important areas of learning by becoming involved in this type of work. These opportunities can be summarised as follows:

- Values and behaviour congruence learning how this feels as well as understanding the analysis of the process and the emotional content.

- Professionalism

the difference between bureau-professionalism and social work professionalism. Developing clarity about the centrality of the worker-service user relationship, and understanding the analysis of any social work practice in terms of professional practice, that is the relational context, knowledge acquisition, theory to practice, values and autonomy.

- Ethics of care what this is and learning how to apply it.

- Opportunities to directly meet SiSWE explicit requirements within the SiSWE expect students to learn how to make positive relationships with service users, practice in an ethical manner and underpin their practice with knowledge and understanding.

In bringing the main areas of suggested learning together, it becomes apparent that the quality of the learning will depend very much not only on the ability of the student, but also on the practice educator working with the student. The practice educator must be fully informed and knowledgeable about all of the above, as well as sensitive to the process that the student

27 J. of Practice Teaching \& Learning 11(1), pp.19-36. DOI: 10.1921/ 175951511X651913. @ wEbb 
is likely to go through. It will be fundamental that the practice educator is supportive of why the students are being asked to undertake personal care tasks, and that they can help the student reflect, analyse, build new knowledge and make best use of these profound learning opportunities. A practice educator will also need to help the student make explicit links from personal care to the SiSWE.

\section{Methodology}

Seven students were placed in private sector residential establishments and all undertook personal care tasks. The extent of involvement in personal care varied from hair washing and dressing, manicures and pedicures to the full range of bathing, showering and toileting. All students had some experience of undertaking 'intimate' personal care of some type. Six out of the seven students were in their third year of the BA in social work degree, and one was in her fourth year.

All students were asked to attend, voluntarily, for a semi-structured interview lasting around half an hour. Ethical approval had been sought from the university and students were fully informed of the study with options to opt out before they agreed to take part or at any time thereafter.

Semi-structured interviews were chosen as the most suitable data collection method as they allow the interviewer to "probe beyond the answers' (May, 1993 p. 93). This meant that the interviewer would ask the questions as per the interview schedule, but had latitude to ask for elaboration or clarification. All interviews were audio recorded and transcribed.

The authors undertook analysis of the interview transcripts by collating the answers under each of the question headings, then looking for themes within each section. These themes are explored below.

\section{Results and discussion}

\section{Values and behaviour congruence}

The authors drew a hypothesis from the literature on values and behaviour

28 J. of Practice Teaching \& Learning 11 (1), pp. 19-36. DOI: 10.1921/ 175951511X651913. @ w\&b 
congruence that students might transit through 3 phases of feelings: from feeling negatively to actual 'doing' to positive feelings of satisfaction. Results showed that 5 out of 7 students had never undertaken personal care with non-family members and 4 out of those 5 felt very negatively about the prospect of their PLO, especially anticipating the undertaking of personal care with a stranger eg. 'I actually cried when I heard I had to do personal care' and 'I was originally terrified'. 3 students spoke about quite extreme reactions. It would seem, therefore, that phase 1, feeling negatively, was indeed demonstrated by the distress felt by the students in the study. This also resonates with the findings of Quinn (1999) and Hughes and Haycox (2006) as explored earlier in the paper.

During phase 2, the actual doing, students became familiar with the tasks, observed others doing the work and gradually began to do it themselves. The overwhelming finding from this area of the study was that students, without exception, highlighted the relationship with the resident as the most important feature. Students spoke about the fact that having a relationship or bond with the resident made undertaking personal care so much easier (it felt like a natural part of the relationship) and that undertaking personal care helped to build and strengthen already existing relationships. Thus, students highlighted the importance of the relationship on two crucial levels. The authors had suggested that students should be concerned with building relationships with the residents, but the profound effect that personal care had upon this issue was not foreseen. Also, this finding is entirely in tune with the literature on professionalism and an ethics of care approach: that the relationship is of crucial importance. Students said: "My feelings changed fairly quickly. I got to know all 3 residents and made a relationship that really helped - an open and honest relationship with them' and 'I started to build a relationship first and things got easier'. They also stated that: 'Helping with personal care helped me get to know the person better' and 'I built up a really good relationship through personal care'.

Finally, phase 3, did the students feel satisfied, having 'helped' satisfactorily? Without exception, the students said they found the experience of undertaking personal care positive, and several of them wanted to speak to other students about to embark on a similar PLO, to reassure them. Several students also felt that every student should have such an experience. The five who had felt very negatively in the beginning made statements such as: 'Not being able to help someone when they are in difficulty is upsetting', 'It was satisfying as I got close to her', 'Really

29 J. of Practice Teaching \& Learning 11 (1), pp.19-36. DOI: 10.1921/ 175951511X651913. @ wE-b 
fulfilling - just knowing you could help someone with such a basic need' and 'I felt proud to be doing personal care, satisfied that I had made a difference'. These comments, which very much typify all of the students' feelings, give significant validation to the suggestion that students would feel positive once they had achieved value and behaviour congruence. From the exploration of the literature, especially Kosny and Eakin's (2008) work, it can be strongly suggested that, by being able to help, to get alongside service users, to build a relationship and to be responsive to needs, workers can achieve real feelings of satisfaction as this behaviour is exactly in tune with their values.

\section{Values and knowledge}

Students were asked what their main areas of learning were from undertaking personal care. Overwhelmingly, students talked about learning in a profound way about values such as 'treating people with dignity and respect', 'I learned about putting service users' needs first', 'promoting dignity' and 'partnership with service users'. The importance of values and, once again, the centrality of the relationship, were highlighted within all of the answers to the interview questions.

Less positively, only one of the students discussed learning in the context of building an academic knowledge base. The particular student who did was the only fourth year student in the group and she talked about learning to 'understand dementia and apply it to how I did personal care, for example at the pace of the service user'. None of the other students made any mention of gaining this type of knowledge.

Associated to this, students were asked what they drew on to help them undertake personal care. Again, all students talked about a strong and explicit value base contextualising the task and, again, 6 out of 7 students did not draw on formal knowledge to any significant extent: for example, 'person centred 'things', 'relationships and health and safety', 'promoting dignity, but no theory used' and 'respect and Codes of Practice'. Again, the exception to this was the fourth year student who said 'I drew on knowledge about loss and change, dementia, relationship building, 'third object theory' ....'

This is an important finding and is linked to the discussion in the literature review about professionalism. According to Van Lanen (2008) to be a professional involves having the specialised knowledge required

30 J. of Practice Teaching \& Learning 11(1), pp.19-36. DOI: 10.1921/ 175951511X651913. @ w\&b 
for the work. It would seem that there is a vast difference between just doing a personal care task, albeit in a value based and respectful way, and doing it in a way underpinned by knowledge about what it might mean for the resident. When is a personal care task not just a task? Perhaps when theories of loss, of life stages and transitions, and knowledge about self-esteem and self-image, and aging help a student or a worker undertake the task in a way that is fully informed? It could be suggested that this is the area where student social workers could identify the professional 'social work' in a PLO so often associated with social care, and yet only one of them did that. It may be that the fourth year student was at a stage in her degree where the explicit application of knowledge is an accepted requirement, but that third year students required more support to develop and apply knowledge retrospectively to the task. However, by the time the students were interviewed the authors' expectations were that they would have integrated this type of knowledge, but clearly they had not done so. The crucial role of the practice educator was highlighted earlier in this paper, and perhaps more work needs to be done with practice educators in these particular settings to emphasise the importance of the underpinning knowledge base for personal care.

\section{Links to the Standards in Social Work Education (SiSWE) and student assessment}

When asked whether they had written about their experience of personal care for assessment purposes, 5 out of 7 said they had not matched it to the SiSWE. It seems they did not see the explicit learning opportunities associated with personal care tasks nor did they relate new knowledge and understanding to the assignment task. One student said, 'I thought it wasn't good evidence for the SiSWE' which suggests personal care tasks were not afforded high status within their own learning hierarchies. Students focused well on their assignment tasks with 6 out of the 7 students passing both their practice and articulation of practice so it was perplexing to discover that what they considered to be rich seams of personal learning were generally not 'mined' for incorporation within their final assessed work.

Why the SiSWE were evidenced by students using examples from other areas of their practice rather than those arising from personal care tasks may link back to the finding that most of the students in this study were resistant

31 J. of Practice Teaching \& Learning 11(1), pp.19-36. DOI: 10.1921/ 175951511X651913. @ wEb 
to the idea of working in a residential setting, particularly with older people, and had felt that it was not 'proper social work'. They had also shown fear and anxiety about having to do personal care tasks. Although in practice they had embraced opportunities to fully engage with people and build positive relationships, some even seeing it as a life changing experience, the requirement to link practice to theory and acquire new knowledge was missing (as previously discussed) and therefore rendered their experience of personal care poor evidence for inclusion in their written work. It also appears that specific, more formal tasks which the students associated with 'real' social work were the ones which they studied, acquiring new knowledge and consequently producing as evidence. The focus on these more formal tasks may have, again, eroded the recognition of their learning in relation to relationship building, showing respect, providing privacy and all the other skills, knowledge and understanding they acquired through engaging in personal care tasks.

The above finding again illustrates that students did not draw on knowledge to underpin personal care, nor did they identify real learning from it (and therefore did not see links to SiSWE). As above, students need help to raise the idea of personal care from 'doing' a task to the real learning experience it can offer.

\section{Professionalism and caring}

All students generally had a sense of some aspects of professionalism, defining this as being trustworthy, punctual, reliable and upholding the codes of practice. They also recognised a sense of autonomy by describing being professional as 'reflecting' and thinking for themselves rather than just following orders. Status featured in their responses with one student stating, 'when others 'assumed' I was 'just' a care assistant I didn't feel professional' and another noted, 'social care tasks made me feel less professional as a social worker'. One student chose to wear a uniform whilst on her PLO which she said made her feel more professional whilst another described professionalism as being asked her opinion by others and being on a qualifying social work programme - 'having the training.' Another student drew a range of concepts together describing her sense of professionalism as being knowledgeable, respectful, treating people with dignity, 'In that setting being a professional was being someone they could get answers from, putting them first and treating them as an individual.'

32 J. of Practice Teaching \& Learning 11(1), pp.19-36. DOI: 10.1921/ 175951511X651913. @ w\&b 
The above findings resonate with earlier suggestions by Van Lanen (2008) that professionals are people who are autonomous and in possession of the specialised knowledge required for their work. The students certainly felt professional when they had specific knowledge, but, once again, the students did not identify that they needed a broader, academic knowledge base to properly inform the doing of the 'task' and, thus, did not link personal care to notions of professionalism.

When asked how important the caring aspect is within the social work profession, overwhelmingly, 7 out of 7 students echoed the sentiment of one student who said, 'You have to care to make a difference. This placement has heightened that for me.' All of the students said that the experience made them think more about 'caring' in the wider social work world. A heightened awareness of caring as a central concept in social work, together with the realisation that the relationship between worker and service user is absolutely core, is entirely in sympathy with an 'ethics of care' approach. The students did not recognise this framework explicitly but had learned the importance of its defining features, and had put them into action.

\section{Conclusion}

In answer to the question 'can undertaking personal care within PLOs enhance the learning of student social workers,' the authors would give an emphatic 'yes.' Learning enhancement was particularly obvious in the areas of understanding the centrality and importance of service userworker relationship and the importance of caring. Students were able to generalise those particular aspects of their learning from personal care to the wider social work world. The authors feel that this is of critical importance, especially in regards to counterbalancing "pervasive and corrosive managerialism' (Meagher and Parton, 2004, p. 11). To keep the relational aspect of social work at the forefront of our work, new social work professionals must understand the importance of it, and its place at the heart of true social work professionalism.

Learning for students was also clearly demonstrated as they moved from initial reluctance about their PLO settings and the idea of undertaking personal care tasks, to absolutely seeing the positives and feeling the 'rightness' of value/behaviour congruence, that is, the 'rightness' of being able to help. To re-iterate the feelings of one particular student in relation

33 J. of Practice Teaching \& Learning 11(1), pp.19-36. DOI: 10.1921/ 175951511X651913. @ wEb 
to personal care: '(it was) really fulfilling - just knowing you could help someone with such a basic need.' There is learning for students in the recognition of what value/behaviour congruence feels like, and thus, what the opposite (disjuncture) feels like. When values and behaviour are incongruent, students should be helped to recognise that that unsettled, worrying feeling needs to be attended to and explored: 'why do I feel this way? If values and behaviour are out of synch, what does that say about the practice I am involved in? I need to analyse the situation further'. This aspect of student learning was not maximised within our study, and practice educators would need to be fully aware of the concept in order to help students understand it. Becoming an emotionally intelligent worker depends on such insight, critical analysis and reflexive practices.

Where learning was not enhanced was in the area of grounding practice with reference to knowledge and theory. Administering intimate personal care to another person is an extremely important and sensitive area of work, and yet students did not feel that they needed to learn about, and use, formal academic knowledge about what it might mean to a person to be in a position of requiring such care. Life transitions, loss, ageing, dementia and the like are all areas of knowledge which would have been relevant to the task, and yet the students did not use the opportunity to undertake learning in these areas. The students did demonstrate autonomy, however, and this is heartening.

To be an emerging social work professional, students need to demonstrate all of the features of professional social work practice already outlined. We can see that some aspects of professionalism were undoubtedly enhanced by undertaking personal care, whereas others, although they have the potential to be maximised, simply were not. Once more, the importance of the role of the practice educator is of crucial importance, and clearly something which is an area for development.

Finally, the authors are aware that there was no control group for this study. Might it be that students could have learned all of the things they did without undertaking personal care tasks? This might be the case, but the authors believe that being afforded the privilege of such intimate engagement with another human being does intensely heighten core aspects such as the relationship, values and value/behaviour congruence. The relationship is so important during this type of contact that students themselves were unprepared for the profound effect it had on the actual strengthening of the bond they had with the service user: 'I built up a really good relationship through personal care.' It is suggested that the quality of

34 J. of Practice Teaching \& Learning 11(1), pp.19-36. DOI: 10.1921/ 175951511X651913. @ w\&b 
the relationship, from the service user's perspective as well as the student's, is of even more importance within personal care than it might be in other learning opportunities the student might experience.

To put in context these particular learning opportunities for students, we must, as social work educators, reassess curriculum content, taking cognisance of the personalisation agenda and the importance of a strong emphasis on relationship and power sharing with service users (Beresford, 2000; Social Care Institute for Excellence, 2007; Scottish Government, 2010). Any learning experience that can enhance student learning in those areas is clearly extremely valuable.

\section{References}

Association of Directors of Social Work (ADSW) (2009) Code of Practice and Ethics. at: http://www.adsw.org.uk/home.aspx?MicrositeID $=1 \& S e a r c h=1$ [Accessed 14th Feb 2011]

BASW (British Association of Social Workers) (2010) Code of ethics at http://www. basw.co.uk/about/code-of-ethics/ [Accessed 7th February 2011]

Beresford ,P (2000) User's Knowledge and Social Work Theory. British Journal of Social Work 30, 4, 489-503

Calderwood, K., Harper, K., Ball, K., and Laing, D. (2009) When values and behaviour conflict: Immigrant BSW students' experiences revealed. Journal of Ethical and Cultural Diversity in Social Work, 18, 110-128

Care Commission (2007) National Care Standards: Care home for older people at http://www.nationalcarestandards.org/74.html [Accessed 7th February 2011]

DiFranks, N.N. (2008) Social Workers and the NASW Code of Ethics: belief, behaviour and disjuncture. Social Work, 53, 2, 167-176

Fenton, J. (2011) Bringing together messages from the literature on criminal justice social work and 'disjuncture': the importance of 'helping.' British Journal of Social Work, 1-16 doi:10.1093/bjsw/bcr136

Horner, B and Kelly, T.B. (2007) Ethical decision making in the helping professions: a contextual caring approach. Social Thought: Journal of Religion \& Spirituality in Social Work, 26, 1, 71-87

Hughes, M and Haycox, K (2006) Knowledge and interest in ageing: a study of final-year social work students. Australasian Journal on Ageing, 25, 2, 94-96

Jones, C. (2001) Voices from the front line: State social workers and new labour. British Journal of Social Work, 31, 547- 562

35 J. of Practice Teaching \& Learning 11(1), pp.19-36. DOI: 10.1921/ 175951511X651913. @ wEb 
Kosny, A. and Eakin, J. (2008) The hazards of helping: work, mission and risk in non-profit social services organizations. Health, Risk and Society, 10, 2, 149-166 Manning, R.A. (1998) A care approach. in Kuhse, $\mathrm{H}$ and Singer, P (Eds.) A Companion to Bioethics. Malden MA: Blackwell

May, T. (1993) Social Research: Issues, methods and process. Buckingham: Open University Press

Meagher, $G$ and Parton, N (2004) Modernising social work and the ethics of care. Social Work and Society 2, 1, 10-27

O'Donnell, P., Farrar, A., Brintzenhofeszoc, K., Conrad, A. P., Danis, M., Grady, C., Taylor, C,. and Ulrich, C. (2008) Predictors of ethical stress, moral action and job satisfaction in health care social workers. Social Work in Health Care, 46, 29-51

Quinn, A (1999) The use of experiential learning to help social work students assess their attitudes towards practice with older people. Social Work Education, $18,2,171-182$

Royal Commission on Long Term Care (1999) With Respect to Old Age: Long term care - rights and responsibilities. London: HMSO

Sawyer, A. (2010) 'Mental health workers negotiating risk on the front line'. Australian Social Work, 62, 441-459

Scottish Government (2003) The framework for Social Work Education in Scotland. Edinburgh: HMSO

Scottish Government (2010) Self Directed Support: A national strategy for Scotland. Edinburgh: HMSO

Scottish Social Services Council (SSSC) (2009) Codes of Practice For Social Services Workers and Employees. Dundee: SSSC

Schwartz, W. (Ed:Berman-Rossi T) (1994) Social Work: The Collected Writings of William Schwartz. Itasca, IL: F.E. Peacock

Social Care Institute for Excellence (SCIE) (2007), The Changing Roles and Tasks of Social Work: A literature informed discussion paper, London, SCIE

Van Lanen, M.T.A. (2008) Peeping at peers: a cross-national study of professionalism in social work. European Journal of Social Work, 11, 4, 469-473

36 J. of Practice Teaching \& Learning 11(1), pp.19-36. DOI: 10.1921/ 175951511X651913. @ w\&b 